\title{
REGRESSO E CIRCULAÇÃO DE EMIGRANTES PORTUGUESES NO INÍCIO DO SÉCULO XXI
}

\author{
Isabel Tiago de Oliveira \\ Instituto Universitário de Lisboa (ISCTE-IUL), Centro de Investigação e Estudos de Sociologia \\ (CIES-IUL), Lisboa, Portugal \\ Pedro Candeias \\ Instituto de Ciências Sociais (ICS), Universidade de Lisboa, Lisboa, Portugal \\ João Peixoto \\ Instituto Superior de Economia e Gestão (ISEG), Centro de Investigação em Sociologia Económica \\ e das Organizações (SOCIUS/CSG), Universidade de Lisboa, Lisboa, Portugal \\ Joana Azevedo \\ Instituto Universitário de Lisboa (ISCTE-IUL), Centro de Investigação e Estudos de Sociologia \\ (CIES-IUL), Lisboa, Portugal \\ Jorge Macaísta Malheiros \\ Instituto de Geografia e Ordenamento do Território (IGOT), Universidade de Lisboa, Lisboa, Portugal
}

\begin{abstract}
Resumo O principal objetivo deste artigo é avaliar a importância do regresso de emigrantes portugueses durante a década de 2001-2011, tendo em conta o volume do regresso, os perfis sociodemográficos, as variações por países de emigração e a emergência de novas formas de mobilidade. Um objetivo particular consiste em produzir uma tipologia das formas de regresso: algumas mais associadas à visão tradicional da emigração na idade ativa e regresso na fase da reforma, outras indiciadoras de movimentos de tipo diferente, com regressos mais precoces durante a vida ativa. A observação de dados recentes permite descortinar algumas das novas modalidades de emigração, incluindo uma tendência crescente para a circulação.
\end{abstract}

Palavras-chave Portugal, emigração, regresso, transnacionalismo, circulação.

Abstract This text's main objective is to assess the importance of the return of Portuguese emigrants in 2001-2011, in the light of the number of people who came back, their sociodemographic profiles, the variations in the countries they came from, and the emergence of new forms of mobility. A more particular goal is to produce a typology of forms of return: some more associated with the traditional view of people emigrating when they are of working age and coming home in the retirement phase of their lives; others that suggest movements of a different type, with earlier returns while the returnee is still working. The authors also look at how an increase in complex mobility patterns can lead to a different pattern of returns. Recent data reveal some of the new mobility formats, including a growing trend towards circulation.

Keywords Portugal, emigration, return, transnationalism, circulation.

Résumé Le principal objectif de ce texte est d'évaluer l'importance du retour des émigrés portugais au cours la décennie 2001-2011, compte tenu du nombre de retours, des profils sociodémographiques, des variations par pays d'émigration et de l'émergence de nouvelles formes de mobilité. Un objectif particulier est de produire une typologie des formes de retour: certaines plus associées à la vision traditionnelle de l'émigration à l'âge actif et du retour à l'âge de la retraite, d'autres révélant des mouvements d'un type différent, comme les retours plus précoces à l'âge actif. En outre, le développement de modèles complexes de mobilité peut donner lieu à différentes logiques de retour. L'observation de données récentes permet de déceler certaines des nouvelles modalités de déplacement, notamment une tendance croissante à la circulation.

Mots-clés Portugal, émigration, retour, transnationalisme, circulation. 
Resumen El principal objetivo de este texto es evaluar la importancia del regreso de emigrantes portugueses durante la década de 2001-2011, teniendo en cuenta el volumen del regreso, los perfiles sociodemográficos, las variaciones por países de emigración y la emergencia de nuevas formas de movilidad. Un objetivo particular es producir una tipología de las formas de regreso: algunas más asociadas a la visión tradicional de la emigración en la edad activa y regreso en la etapa de la jubilación, otras indiciadoras de tipos distintos de movimientos, con regresos más precoces en la vida activa. Además de esto, el incremento de patrones complejos de movilidad puede originar un diferente patrón de regresos. La observación de datos recientes permite revelar algunas de las nuevas modalidades de desplazamiento, incluyendo una tendencia creciente para la circulación.

Palabras-clave Portugal, emigración, regreso, transnacionalismo, circulación.

\section{Introdução}

Apesar da sua importância, os estudos sobre o regresso de emigrantes não assumiram, ao longo das décadas, um papel de grande destaque nas teorias migratórias. ${ }^{12}$ Na maioria dos trabalhos dedicados às migrações contemporâneas assume-se, pelo menos implicitamente, a unidirecionalidade dos fluxos: o estudo da emigração, a partir do país de origem, ou do da imigração, na perspetiva do país de chegada, é efetuado sem preocupação com a eventual reversão do percurso migratório. É certo que o facto de o retorno poder suceder num prazo muito extenso, ao longo do ciclo de vida do migrante, dificulta a operacionalização da investigação. Em qualquer caso, a teoria raramente deu prioridade ao tema. O melhor exemplo é o das obras clássicas sobre imigração, com relevo para as de tradição norte-americana, que assumiram que a integração implicava uma mudança definitiva de residência - situação que o paradigma da "assimilação" ilustra de forma emblemática (e.g., Park e Burgess, 1921). Seriam sobretudo os projetos migratórios fracassados que incluiriam um regresso (Cassarino, 2013). Porém, no caso das migrações intraeuropeias do pós-guerra,

1 Este artigo foi produzido no âmbito do projeto de investigação "Regresso ao futuro: a nova emigração e a relação com a sociedade portuguesa" (REMIGR), realizado por uma equipa do SOCIUS/CSG, ISEG, Universidade de Lisboa; CEG, IGOT, Universidade de Lisboa; CES, Universidade de Coimbra; e CIES, Instituto Universitário de Lisboa (ISCTE-IUL). O projeto (PTDC/ATP-DEM/5152/2012) foi financiado pela Fundação para a Ciência e a Tecnologia (FCT). Os autores agradecem os contributos dos restantes membros da equipa, nomeadamente Paulo Miguel Madeira, José Carlos Marques, Pedro Góis, Bárbara Ferreira, Alexandra Ferro, Aline Schiltz e Eugénio Santana, bem como os comentários de um revisor anónimo. Todos os erros e insuficiências são, porém, de sua inteira responsabilidade.

2 Na bibliografia portuguesa, o uso dos termos "regresso" ou "retorno" de emigrantes é quase indiferente. O termo "retorno" tem sido utilizado muitas vezes para descrever o caso dos portugueses (quer os naturais de Portugal, quer os seus descendentes) provenientes das ex-colónias no momento da descolonização - os designados "retornados" (Pires et al., 1984). Rocha-Trindade (1983) tentou mesmo diferenciar o "retorno", quando o movimento é compulsivo, do "regresso", quando o movimento é voluntário. Mas algumas obras marcantes no estudo da emigração têm também usado o termo "retorno" para descrever os regressos voluntários a Portugal (ver, por exemplo, Silva et al., 1984, e Monteiro, 1994). Em alguns casos, os termos foram usados indistintamente pelo mesmo autor e no mesmo ano (ver, por exemplo, Poinard, 1983a e 1983b). Neste texto, os termos "regresso" e "retorno" serão também usados de modo equivalente. 
supostamente organizadas segundo uma lógica temporária, os anos subsequentes ao encerramento formal do ciclo migratório em 1973/74, que envolveu bastantes regressos, levaram ao aparecimento de diversos trabalhos sobre o retorno (King e Christou, 2011), de que são exemplo os estudos de Poinard (1983a e 1983b) e Silva et al. (1984), para Portugal, de Pascual de Sans (1983), Álvarez Silvar (1997) e Vilar (2003), para a Espanha, ou de Unger (1986), para a Grécia.

Nos últimos anos, em grande medida como consequência da difusão da teoria do transnacionalismo, o panorama alterou-se, sendo crescentes as referências a padrões múltiplos de mobilidade. Estes incluem um peso assinalável de regressos ao país de origem, muitos casos de migração temporária (com saídas e regressos repetidos ao longo do tempo), percursos complexos de reemigração entre diferentes países, e múltiplas residências e atividades, onde a deslocação internacional deixa de assumir a inércia e a monotonia dos movimentos do passado (Cavalcanti e Parella, 2013; Carling e Erdal, 2014). Mais do que o conceito clássico de migração, hoje tende-se a enfatizar o peso da mobilidade e da circulação.

No caso português, os estudos sobre o regresso têm sido significativos, mas nunca atingiram a relevância dos que se referem às saídas (Rato, 2001; Candeias, Ferreira e Peixoto, 2014). Quando se observa a produção científica sobre o tema nas últimas décadas, verificamos que a investigação tem focado sobretudo o regresso dos "brasileiros", em finais do século XIX e início do século XX (e.g., Alves, 1994; Piloto 2010), o regresso dos emigrantes europeus após a Segunda Guerra Mundial e após a mudança económica de meados dos anos 70 do século XX (e.g., Antunes, 1981; Poinard, 1983a). Curiosamente, os estudos são notoriamente escassos para as décadas mais recentes, quando se começou a discutir a circulação e o transnacionalismo. Eles são ainda mais escassos no que se refere à primeira década do século XXI, quando a emigração portuguesa se reanimou (Pires et al., 2010).

Este texto procura preencher esta lacuna na investigação. O seu principal objetivo é avaliar a importância do regresso de emigrantes portugueses nos últimos anos, em particular durante a década de 2001-2011, tendo em conta o volume do regresso, os perfis sociodemográficos, as variações por países de emigração e a emergência de novas formas de mobilidade. Um objetivo particular é produzir uma tipologia das formas de regresso: algumas mais associadas à visão tradicional da emigração na idade ativa e regresso na fase da reforma, outras indiciadoras de movimentos de tipo diferente, com regressos mais precoces na idade ativa. Um dos problemas a equacionar é o facto de a emigração assumir diferentes perfis, em vários períodos do tempo e em vários países de destino, o que pode implicar novos perfis de emigrantes regressados. Espera-se, precisamente, que a emigração ocorrida nos anos mais recentes possa originar novas características do regresso. Para além disto, o incremento de padrões complexos de mobilidade pode originar um diferente padrão de regressos. A observação de dados recentes pode descortinar algumas das novas modalidades de deslocação, incluindo uma tendência crescente para a circulação.

O texto encontra-se dividido em três partes. Na primeira será efetuado o enquadramento teórico do problema, examinando as teorias sobre o regresso e a circulação migratória, bem como a investigação acumulada em Portugal. Na segunda 
será descrita a metodologia utilizada. Na terceira serão examinados os resultados do estudo empírico, baseados sobretudo em material proveniente do Censo de 2011. Num primeiro momento apresentam-se os volumes do regresso e as características sociodemográficas dos emigrantes regressados, de acordo com o país de emigração; num segundo momento é efetuada uma análise de clusters, que agrega os emigrantes regressados em grupos homogéneos; finalmente, avaliam-se as taxas de regresso por países de emigração e problematiza-se o fenómeno da migração circular.

\section{Enquadramento}

\section{Teorias sobre regresso e circulação}

A noção de "regresso" de migrantes está relativamente bem consolidada na literatura existente. Aideia de que o regresso implica uma fixação definitiva ou, pelo menos, uma permanência de longa duração no país de origem está na base da maior parte dos estudos sobre o tema. Mesmo trabalhos recentes, como o de King e Christou (2011: 452), indicam que a migração de retorno (return migration) deve ser entendida como "a physical relocation of the migrant with the intention of staying for some time, maybe permanently, in the place of origin". É verdade que, como discutiremos à frente, esta noção tem sido questionada, enfatizando-se a fluidez e o caráter temporário de muitos movimentos de retorno. Ainda assim, na maior parte dos casos, o regresso é apresentado como relativamente duradouro (como sucede com a própria emigração).

Podemos admitir que o estudo do regresso é tão antigo como o da emigração. A emigração de retorno era já apontada nas leis das migrações de Ravenstein, quando referia que "each main current of migration produces a compensating counter-current" (Ravenstein, 1885: 199). Vários estudos sobre a emigração foram, também, provando que o retorno sempre fez parte da experiência migratória, mesmo quando não se concretizava. Por exemplo, a propósito da emigração portuguesa para França, Rocha-Trindade (1983: 89) escreveu que, "para além de um facto concretizado, o Retorno constitui uma ideia e um objetivo, geralmente presente desde o momento da primeira partida". Sayad (2000), com base em reflexões sobre a migração magrebina para França, demonstra que o retorno é um "elemento constitutivo da condição do imigrante", acompanhando todo o projeto migratório. Segundo ele, o retorno tende a adquirir uma forma ilusória, porque o contexto de partida passa a ser mais imaginado do que real. Monteiro (1994), no estudo etnográfico levado a cabo sobre os portugueses em Connecticut, nos EUA, entende o retorno como reflexo do imaginário e da retórica, tanto dos que partem, como dos que ficam, mas que raramente se concretiza. Esta ideia é ainda suportada por outros estudos, como o dos senegalenses emigrados em Itália (Sinatti, 2011).

Observando a evolução do número de referências, o interesse da academia pelo retorno de emigrantes é relativamente recente. Segundo Cassarino (2013), teve o seu início nos anos 60 do século passado. As referências aumentaram na 
década seguinte, quando se registaram os primeiros movimentos de retorno de elevado porte, com o choque petrolífero dos anos 70 e a mudança económica que lhe sucedeu. Este acontecimento interrompeu o recrutamento de migrantes laborais para os países da Europa Ocidental, o que afetou especialmente os trabalhadores oriundos de países mediterrânicos. Datam do início dos anos 80 processos de estímulo ao regresso por parte das autoridades dos países de acolhimento. O fenómeno levou a que se produzisse um quantitativo elevado de literatura sobre o tema (King e Christou, 2011) - o que, como veremos, também se passou em Portugal. Gradualmente, o foco dos estudos académicos sobre os regressos passou a incidir nos impactos do retorno nos países de origem (Cassarino, 2013).

Já na década de 2000 deu-se um recrudescimento do interesse pelo tema, não tanto pela sua relevância estatística, mas mais pela sua reconceptualização teórica (King e Christou, 2011). Tal resultou, sobretudo, do aumento das referências ao transnacionalismo migrante. A relação desta perspetiva teórica com os regressos é substancial, colocando em causa a forma clássica de o pensar (Cavalcanti e Parella, 2013; Cassarino, 2013; Carling e Erdal, 2014). A ideia de que podem existir múltiplos regressos (e partidas), ou a de que as duplas residências se vulgarizam, diminuem a capacidade heurística das teorias que encaravam o regresso como "permanente" e definitivo. Neste sentido, chamou-se a atenção para as "fronteiras porosas" entre o retorno de longa duração e as visitas frequentes, colocando em causa o paradigma clássico do estudo dos regressos (Carling e Erdal, 2014).

Por seu lado, o conceito de migração circular é entendido na bibliografia contemporânea como "the systematic and regular movement of migrants between their homelands and foreign countries, typically seeking work" (Constant e Zimmermann, 2011: 498). A sua adaptação às migrações internacionais tem obrigado a romper com a teoria clássica, que toma habitualmente a migração como um movimento permanente (Constant e Zimmermann, 2011). A migração circular costuma ser aferida através da dupla residência e ligação a mais do que um local (Posel e Marx, 2013). Neste sentido, Duany (2002: 360) afirma que "such dual or multiple residences allow circular migrants to combine various sources of support from work, family, and the state".

A ideia de uma crescente circulação dos migrantes é anterior às teorias do transnacionalismo, embora se tenha vindo progressivamente a cruzar com elas. Provavelmente, a primeira referência teórica é a de Zelinsky (1971), na sua teoria da transição para a mobilidade (mobility transition), quando afirma: "circulation denotes a great variety of movements, usually short-term, repetitive, or cyclical in nature, but all having in common the lack of any declared intention of a permanent or long-lasting change in residence" (Zelinsky, 1971: 226). Em termos operatórios, o conceito foi inicialmente utilizado para cunhar as migrações internas de sentido rural-urbano, durante os anos 70 do século XX (Hugo, 1977). Entendeu-se nessa altura que as migrações circulares se caracterizam por descrever movimentos de pessoas que procuram o país de destino, de forma temporária, por motivos de trabalho ou negócios, normalmente sem a família (Hugo, 1977).

Mais recentemente, a multiplicação das formas de mobilidade temporária e o aumento dos contactos transnacionais vieram dar novo alento a este conceito. 
Durante a década de 2000, para além das teorias do transnacionalismo já referidas, diversos autores iniciaram a tese de que as sociedades contemporâneas protagonizaram uma mobility turn, mudança que cobre não só a mobilidade humana, mas também de capital, de transportes, de informação, de objetos, e ainda a mobilidade social (ver, entre outros, King e Christou, 2011; Faist, 2013). Numa lógica menos abstrata, a proximidade geográfica ou o acesso a meios de transporte permitem uma maior circulação entre países (Hagan, Eschbach e Rodriguez, 2008). A migração circular pode ser ainda uma estratégia de otimização de recursos e um modo de reduzir a ansiedade resultante do facto de o emigrante se encontrar longe da sua família, pois o sujeito mantém as opções em aberto em ambos os países, reduzindo assim os riscos de um compromisso de longo prazo (Constant e Zimmermann, 2011).

Por fim, o processo de integração europeia e a possibilidade de livre circulação no espaço europeu vieram dar origem a um conjunto de análises interessadas em compreender a mobilidade jovem e altamente qualificada dentro da União Europeia, composta por uma minoria de "eurostars" (Favell 2008; Recchi e Favell 2009), com características distintas da maioria dos imigrantes. Numa lógica pós-moderna, as "eurostars" seriam os indivíduos com maiores benefícios de viver num mundo globalizado, em que a liberdade de movimento é tida como um recurso escasso e desigualmente distribuído (Bauman, 1998).

\section{Investigação sobre o regresso em Portugal}

Apesar da sua importância, os estudos sobre o regresso representam uma minoria da produção científica relacionada com a emigração em Portugal. Segundo Rato (2001), os trabalhos sobre o tema são escassos e apresentam grandes lacunas (no mesmo sentido, ver Cairns, Sardinha e Tiesler, 2014). A análise bibliométrica divulgada por Candeias, Ferreira e Peixoto (2014), com base num levantamento bibliográfico sobre a emigração portuguesa referente ao período 1980-2013 (Candeias et al., 2014), indica que estes representam cerca de $8 \%$ do total de referências. Ainda assim, trata-se do sexto tema mais tratado na bibliografia, à frente do mercado de trabalho ou das políticas migratórias. Ainda segundo estes autores, as referências sobre o regresso adquiriram maior peso nos anos 80 do século $\mathrm{XX}$, embora nunca tenham deixado de estar na agenda dos investigadores.

Apesar da sua escassez relativa, o estudo do regresso tem uma longa tradição em Portugal. Um primeiro conjunto de referências incide sobre a emigração portuguesa para o Brasil. Vários trabalhos têm focado, desde há muito, o regresso dos portugueses emigrados para esse país durante o século XIX e o princípio do século XX - os designados "brasileiros" ou "torna-viagem". Esta produção, que ainda hoje se mantém, confirma que mesmo os movimentos transoceânicos do passado não eram irreversíveis. Um segundo conjunto de referências dedica-se ao regresso de emigrantes da Europa após a década de 1970. Em Portugal, à semelhança de outros países emissores, muitos estudos focaram então o regresso e o seu impacto nas regiões de origem (Baganha e Góis, 1998-1999). O trabalho de Silva et al. (1984) é um dos melhores exemplos da produção dessa época, revelando a expectativa de um 
elevado número de regressos - mas, ao mesmo tempo, relativizando o seu impacto no desenvolvimento nacional e regional.

Os estudos sobre os regressos ocorridos no último quartel do século XX estabeleceram ainda algumas indicações importantes. Algumas disseram respeito ao perfil dos regressados. Segundo Rato (2001: 165), este podia ser sintetizado da seguinte forma:

sexo masculino, casado e com filhos, ainda em idade ativa, apesar de prolongada permanência no estrangeiro; motivo do regresso : "já ter ganho o suficiente" ou o "desejo de educar os filhos em Portugal"; baixo nível de instrução e de qualificação profissional; regresso à freguesia de origem, onde retomava a atividade agrícola ou ficava inativo; fraca propensão ao investimento produtivo, aplicando as poupanças essencialmente na construção ou compra de casa; principais alterações comportamentais ao nível dos padrões de consumo.

Por exemplo, adotando uma perspetiva comparativa entre Portugal e Espanha, pode destacar-se a análise sobre o regresso de emigrantes na segunda metade dos anos 80 com base nos censos de 1991 (Rallu, Muñoz-Perez e Carrilho, 2000). No caso português, o estudo foca em particular as características sociodemográficas dos regressados de França, Alemanha e Suíça. Nele é revelada a importância quantitativa dos regressos de França, apesar de aqui se encontrarem menores taxas de retorno, mas também o facto de a larga maioria dos regressos ocorrer durante a idade ativa, em que o desemprego é mais frequente que na população residente.

Estes estudos acrescentaram ainda alguns elementos inovadores, ao sublinharem a existência de movimentos repetidos (regressos temporários), transnacionalismo crescente e maior circulação. A expressão "vaivém" foi nessa altura cunhada para caracterizar os regressos temporários e as visitas frequentes, antecipando assim os argumentos transnacionalistas que seriam desenvolvidos a partir de meados dos anos 90. Neste sentido, Rocha-Trindade (1983: 89) escreveu que "a vizinhança europeia torna viáveis as visitas anuais que quase assumem aspetos de regressos cíclicos. A decisão de retorno definitivo não é premente, tornando-se, por conseguinte, facilmente adiável". Poinard (1983a) argumentou que o "vaivém" resultava sobretudo da conjuntura económica e política favorável aos movimentos bidirecionais até meados dos anos 70 , sendo depois seguido pela opção entre fixação no destino e regresso definitivo (devido à menor facilidade de emprego e às restrições políticas à reentrada).

A partir do final dos anos 80 do século XX, já depois do acesso de Portugal à União Europeia e com a grande melhoria dos meios de comunicação então verificada, a ideia do "vaivém" seria retomada para caracterizar os movimentos de muitos portugueses na Europa, em particular em França (ver, entre outros, Castro-Almeida, 1989; Cordeiro, 2002). Estes estudos indicaram que o regresso em massa dos portugueses não se iria verificar, sendo substituído por novas formas de mobilidade ou, quando muito, por um regresso apenas após a reforma.

A partir dos anos 80 do século XX, os estudos sobre a emigração assinalaram uma importante viragem quantitativa e qualitativa nos fluxos (Pires et al., 2010). 
Antes de mais, acreditou-se que as saídas se manteriam em níveis residuais - previsão que não se viria a confirmar. Ao mesmo tempo, assinalou-se a grande mudança nas características da emigração. Por um lado, as saídas de longa duração foram, cada vez mais, substituídas por movimentos temporários. Por outro, o perfil dos emigrantes mudou, sendo mais comuns as saídas de contextos urbanos e de população qualificada. Os estudos sobre os regressos ocorridos nesta nova conjuntura, em particular após a viragem do século, são muito escassos. As exceções mais notórias são as dos trabalhos dedicados ao "regresso" da segunda geração (os luso-descendentes, nalguns casos já nascidos nos países de emigração) (e.g., Neto, 2010; Sardinha 2011) e ao regresso de cientistas e investigadores (e.g., Delicado 2010a e 2010b). Permanecem assim quase desconhecidas as tendências de regresso da nova emigração, decorrentes do surgimento de novos perfis de migrantes, novos destinos e um novo contexto mundial das migrações internacionais.

\section{Metodologia}

Para estudar o regresso dos emigrantes portugueses nos anos mais recentes privilegiou-se como fonte o Censo de 2011. No último recenseamento populacional foram efetuadas algumas perguntas que podem ser utilizadas para conhecer as características dos emigrantes regressados. A primeira destas perguntas era: "Alguma vez residiu fora de Portugal por um período contínuo de pelo menos um ano?" Esta era complementada com duas outras questões para quem respondia afirmativamente: qual o país de residência anterior e qual o ano de entrada em Portugal.

Estas perguntas sobre residência anterior foram respondidas positivamente, quer por emigrantes portugueses que regressaram e residiam em Portugal em 2011, quer por imigrantes originários de outros países que viviam em Portugal à data do Censo. Diferenciar estes dois tipos de migrantes obriga a pensar na escolha entre os critérios da naturalidade e da nacionalidade. Optou-se por adotar o primeiro, tendo a análise focado os indivíduos que nasceram em Portugal e responderam afirmativamente à pergunta (isto é, residiram no estrangeiro por um período contínuo de pelo menos um ano). Quem nasceu em Portugal e residiu noutro país é necessariamente um emigrante que regressa, mesmo que a sua nacionalidade não seja portuguesa. A opção pela nacionalidade levaria a trabalhar com uma grande proporção de indivíduos nascidos noutro país, enquanto a seleção pela naturalidade resolve, na prática, o problema (os regressados nascidos em Portugal são sobretudo cidadãos com nacionalidade portuguesa: $98 \%$ ).

A análise sobre o regresso dos emigrantes portugueses efetuada neste texto incide fundamentalmente sobre cerca de 233 mil indivíduos regressados na última década, com especial enfoque na população adulta: cerca de 214 mil indivíduos com pelo menos 20 anos à data do Censo, para os quais se colocam importantes questões relativas ao enquadramento profissional e/ou à condição perante a atividade económica.

Podemos admitir, ainda, que estes valores estão avaliados por defeito, não representando o total de regressos verificados durante a década. A principal limitação decorre do facto de o recenseamento contabilizar apenas os emigrantes que, 
tendo regressado durante a década, não reemigraram até ao momento do Censo. Por outro lado, existirão também emigrantes regressados que morreram antes do momento censitário.

Finalmente, uma vez que não se dispõe dos dados individuais dos emigrantes regressados, toda a análise será efetuada com base nos principais países de onde regressam. Foram considerados os 18 países com mais de 1000 regressos (considerando apenas os indivíduos adultos) e uma categoria residual de "outros". Estes 18 países incluem $94 \%$ da população adulta que regressou na década e fornecem, por isso, uma imagem bastante completa dos regressos segundo o país de emigração.

\section{Regressos e características dos emigrantes regressados}

Entre 2001 e 2011 regressaram cerca de 233 mil emigrantes portugueses ao seu país de origem, dos quais cerca de 214 mil tinham 20 ou mais anos de idade. É sobre esta população em idade adulta que incide a análise. Considerando a dimensão do período, estes valores significam mais de 20 mil emigrantes regressados por ano. Tendo ainda em conta que estes valores se encontram avaliados por defeito, trata-se de um fluxo considerável, quando o comparamos com os fluxos de imigrantes nascidos no estrangeiro ou os de emigração (ver Pires et al., 2010).

Em relação à origem, o país de onde retornaram mais emigrantes na última década é a França, com $27 \%$ do total (quadro 1). Este é também o país com maior stock de emigrantes portugueses e de onde já há muitas décadas regressa o maior quantitativo de emigrantes. Todos os outros países de emigração têm comparativamente muito menor expressão. Muito abaixo situam-se dois outros países de emigração mais recente: a Suíça, para onde se emigrou muito a partir da década de 1980 (Marques, 2008); e a Espanha, um destino importante na última década e onde foram particularmente expressivos os efeitos recessivos da crise (Pinho e Pires, 2013). Logo após, encontram-se os emigrantes que regressam do Reino Unido, sendo este um país para o qual a vaga de emigração é também recente (a partir de 2000) (Pires et al., 2014). A Alemanha, um destino mais antigo da emigração (Pires et al., 2010), é também uma importante origem de emigrantes regressados. Cada um destes quatro últimos países compreende entre $8 \%$ a $13 \%$ dos regressos. Estes cinco destinos europeus representam cerca de $70 \%$ do regresso de emigrantes.

Estes dados confirmam tratar-se de uma contracorrente migratória de regresso muito polarizada em países europeus. Tal reflete, por um lado, o peso histórico de uma emigração de mais longa data (França, Alemanha e Suíça) e, por outro lado, a maior tendência para migrações de menor duração temporal em estados que se constituíram como destino no período mais recente (Espanha e Reino Unido). Países com uma forte história na emigração portuguesa e, por isso, com um grande stock de emigrantes - os EUA, o Canadá e o Brasil -, mas mais distantes geograficamente, possuem comparativamente um peso reduzido nos regressos. É possível que a maior distância e uma conceção da imigração baseada na fixação definitiva propiciem uma maior tendência para a emigração ser mais permanente. 
Quadro 1 Regressos entre 2001 e 2011 por país

\begin{tabular}{lrr}
\hline Países de regresso & Total & $\%$ \\
\hline França & 57.878 & 27,0 \\
Suiça & 27.224 & 12,7 \\
Espanha & 23.790 & 11,1 \\
Reino Unido & 20.747 & 9,7 \\
Alemanha & 17.761 & 8,3 \\
EUA & 10.395 & 4,8 \\
Brasil & 6.307 & 2,9 \\
Luxemburgo & 5.204 & 2,4 \\
Canadá & 5.141 & 2,4 \\
Países Baixos & 4.558 & 2,1 \\
Angola & 4.099 & 1,9 \\
Bélgica & 4.043 & 1,9 \\
Venezuela & 3.839 & 1,8 \\
Itália & 2.311 & 1,1 \\
Andorra & 2.209 & 1,0 \\
África do Sul & 2.168 & 1,0 \\
Moçambique & 1.887 & 0,9 \\
Irlanda & 1.007 & 0,5 \\
Outros & 13.861 & 6,5 \\
Total & 214.429 & 100,0 \\
\hline
\end{tabular}

Fonte: elaborado pelos autores, com base em INE, Censos 2011.

\section{Caracterização}

Os emigrantes regressados na última década apresentam um perfil genericamente similar ao da população residente, embora com algumas diferenças relevantes (quadro 2). ${ }^{3}$ No que se refere à distribuição por sexos, apresentam uma maior percentagem de homens do que a média da população portuguesa, o que estará relacionado com a maior emigração habitualmente verificada no sexo masculino. São também ligeiramente mais jovens, o que aponta desde logo para a importância dos retornos durante a idade ativa e não apenas na fase da reforma - situação já detetada no estudo sobre os regressos na segunda metade dos anos 80 (Rallu, Muñoz-Perez e Carrilho, 2000).

Quanto aos níveis de escolaridade, são relativamente próximos da população em geral, com médias situadas entre 7,3 e 7,8 anos de escolaridade. O trabalho altamente qualificado e o não qualificado assumem valores praticamente idênticos. O mesmo acontece com a proporção de reformados. Uma diferença importante acontece relativamente ao desemprego: os emigrantes regressados apresentam

3 As variáveis analisadas para cada um dos países foram: sexo (percentagem de homens na população com mais de 20 anos); idade (média das idades para a população com mais de 20 anos); escolaridade (indicadores calculados apenas para a população com mais de 20 anos); reformados (percentagem de reformados na população com mais de 20 anos); desempregados (percentagem na população com entre 20 e 60 anos); profissão; profissões qualificadas (percentagem de população nas categorias mais qualificadas - categorias 1 e 2 CNP: "representantes do poder legislativo e de órgãos executivos, dirigentes, diretores e gestores executivos" e "especialistas das atividades intelectuais e científicas"). 
Quadro 2 População regressada entre 2001 e 2011 e população residente

\begin{tabular}{lcc}
\hline & $\begin{array}{c}\text { Emigrantes } \\
\text { regressados }\end{array}$ & $\begin{array}{c}\text { População } \\
\text { residente }\end{array}$ \\
\hline Número total & 233.221 & - \\
Com mais de 20 anos & 214.429 & - \\
Sexo (\% homens) & $58,1 \%$ & $46,9 \%$ \\
Idade (média etária) & 47,7 anos & 50,5 anos \\
Escolaridade (média do n. ${ }^{\circ}$ de anos) & 7,3 anos & 7,8 anos \\
Reformados & $25,8 \%$ & $27,8 \%$ \\
Desempregados & $15,1 \%$ & $10,4 \%$ \\
Prof. qualific. (dirigentes, especialistas intelect./cient.) & $22,1 \%$ & $22,4 \%$ \\
Tecn. interm., administr., serv. pessoais/seg. e vended. & $30,6 \%$ & $39,7 \%$ \\
Trab. agricultura e pesca & $3,5 \%$ & $2,3 \%$ \\
Trabalhos qualificados ind constr., operários inst./maq. e mont. & $29,7 \%$ & $21,8 \%$ \\
Trababalhos não qualificados & $13,6 \%$ & $13,1 \%$ \\
\hline
\end{tabular}

Nota: Os grupos profissionais considerados foram: (a) profissões qualificadas: "representantes do poder legislativo e de órgãos executivos, dirigentes, diretores e gestores executivos" e "especialistas das atividades intelectuais e científicas" (grupos 1 e 2 da CNP); (b) "técnicos e profissões de nível intermédio", "pessoal administrativo" e "trabalhadores dos serviços pessoais, de protecção e segurança e vendedores" (grupos 3, 4 e 5); (c) "agricultores e trabalhadores qualificados da agricultura, da pesca e da floresta" (grupo 6);

(d) "trabalhadores qualificados da indústria, construção e artífices" e "operadores de instalações e máquinas e trabalhadores da montagem" (grupos 7 e 8); (e) "trabalhadores não qualificados" (grupo 9).

Fonte: elaborado pelos autores, com base em INE, Censos 2011.

maior proporção de desempregados do que a população em geral. (também Rallu, Muñoz-Perez e Carrilho, 2000, tinham salientado esta tendência). Porém, como veremos adiante, esta caracterização global dos emigrantes que regressaram na última década esconde as grandes diferenças existentes entre emigrantes que regressam de diferentes destinos (mais e menos recentes) e com diferentes idades (mais e menos jovens).

\section{Idade e reforma}

Os países para onde os emigrantes foram há mais tempo são aqueles de onde eles regressaram mais velhos e mais frequentemente em situação de reforma: França, África do Sul, Canadá, EUA, Alemanha e Venezuela (ver quadro 3). No entanto, é de destacar que enquanto de França os emigrantes voltam mais frequentemente na situação de reforma do que a sua idade faria prever, da Venezuela regressam menos na condição de reformados do que seria de esperar. Atendendo a que são emigrantes com médias etárias próximas é de destacar a importância dos sistemas de segurança social nos países de emigração para explicar esta diferença. ${ }^{4}$ No polo oposto, encontram-se os emigrantes que regressam da Irlanda, de Espanha, Andorra, Itália e Reino

4 Segundo dados do Banco Mundial (The World Bank, 2005: 76-83) a proporção de pessoas cobertas por um esquema de pensões em França era de $88,4 \%$ (dados de 1993), enquanto na Venezuela era de 23,6\% (dados de 1999). Em França, o peso da despesa pública em pensões (não só de velhice) era de $13,4 \%$ do PIB (dados de 1997) e na Venezuela era de 2,7\% (dados de 2001). 
Unido, que são dos mais jovens e possuem uma proporção de reformados muito baixa. Trata-se de países de onde os emigrantes regressam ainda em idade jovem ativa. A correlação entre a idade média dos emigrantes regressados e a proporção que se encontra na situação de reforma é de 0,89 .

\section{Escolaridade e trabalho qualificado}

A escolaridade e a importância relativa do trabalho qualificado também apresentam uma relação quase linear. Quanto maior é o nível médio de escolaridade dos emigrantes que regressaram, maior é a proporção dos que exercem trabalho qualificado em Portugal, sendo a correlação entre as duas variáveis de 0,86. Também aqui se identifica o grupo de países de emigração mais tradicional, tanto a mais antiga como a que se desenvolveu a partir dos anos 80 (França, Suíça, Luxemburgo, Canadá, Venezuela e Andorra): possuem baixos níveis de escolaridade e, quando regressam ao país, encontram pouco trabalho qualificado (ver quadro 3). Na situação oposta, encontram-se os emigrantes que regressam de Itália e de Moçambique - os mais escolarizados e com maior proporção de pessoas empregadas em profissões qualificadas. Ligeiramente abaixo encontram-se os emigrantes que retornam do Brasil e de Angola. Estes últimos, tal como os de Moçambique, apresentam idades atuais entre os 45 e os 50 anos, o que reforça a ideia de se tratar de movimentos com características semelhantes.

\section{Idade e escolaridade}

A análise conjunta da idade e da escolaridade (figura 1) confirma a tendência para os emigrantes das gerações mais antigas apresentarem uma escolarização muito baixa. O caso dos emigrantes retornados de França é o mais saliente (19\% não possuem nenhum nível de ensino e $51 \%$ têm o $1 .$. ciclo), tal como os da Venezuela (13\% e 53\%), África do Sul (11\% e 48\%) e Canadá (12\% e $42 \%)$. Este grupo é constituído por emigrantes bastante mais velhos e muito pouco escolarizados.

Os emigrantes que regressaram da Alemanha, Luxemburgo, Suíça e Andorra também são pouco escolarizados, mas são claramente mais novos que os anteriores. Parece tratar-se de uma emigração na continuidade da emigração tradicional. Ainda em idades semelhantes aos deste grupo de países encontram-se os emigrantes que regressam de países lusófonos. Porém, eles diferenciam-se por apresentarem níveis de escolaridade muito mais elevados.

Finalmente, encontra-se um grupo que, em termos comparativos, é bastante jovem e que tem níveis de escolaridade elevados, se comparado com a emigração tradicional. Neste grupo, os regressados de Itália apresentam os níveis de escolaridade mais elevados. Os emigrantes que retornaram da Irlanda, Reino Unido, Países Baixos, Bélgica e, em menor grau, de Espanha apresentam escolaridades próximas dos emigrantes que regressaram dos países lusófonos, mas distinguem-se por serem mais jovens. 


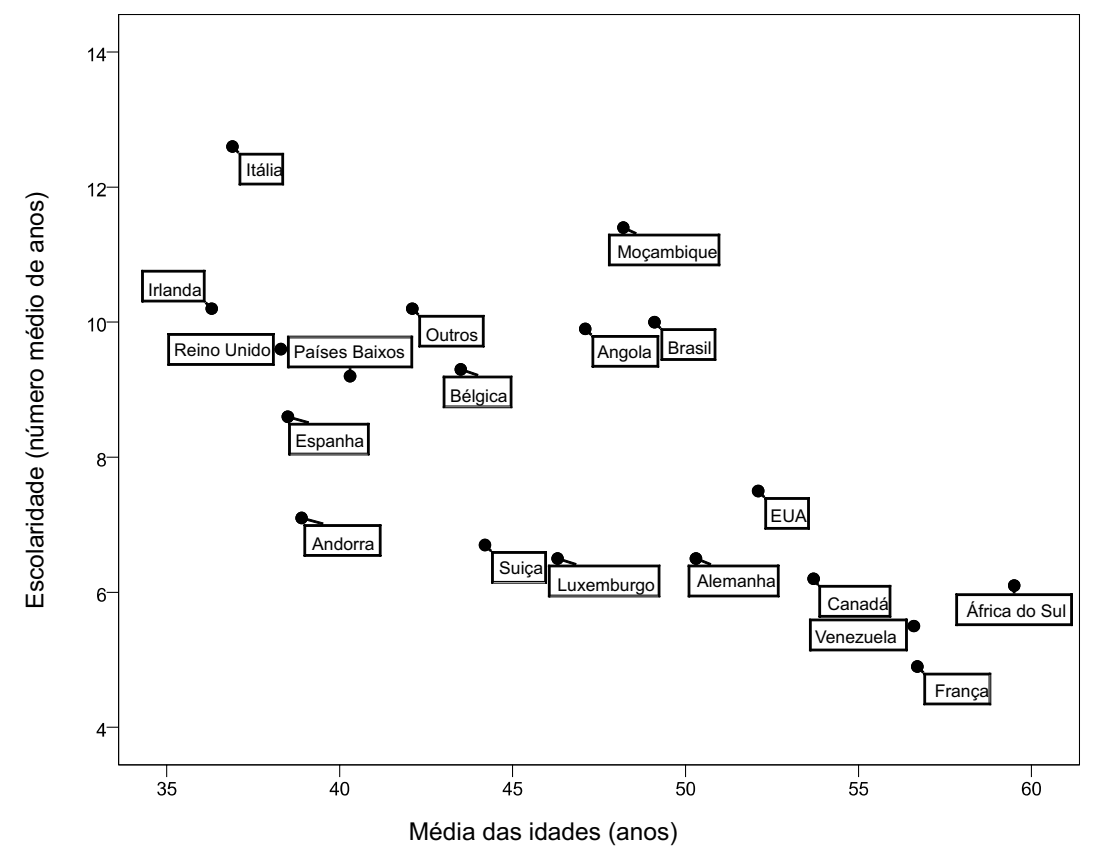

Figura 1 Escolaridade e idade

\section{Desemprego e trabalho qualificado}

A baixa proporção de trabalho qualificado encontrada para os países de onde os emigrantes regressam ainda relativamente jovens e com níveis razoáveis de escolaridade está claramente associada à importância do desemprego em Portugal. A figura 2 mostra como os níveis de desemprego para os emigrantes que voltaram da Irlanda, do Reino Unido, de Espanha e dos Países Baixos estão muito acima dos valores encontrados para os oriundos de outras regiões.

Para os emigrantes que regressam de todos os outros países, os níveis de desemprego são substancialmente mais baixos. Para uns - os de emigração tradicional -, porque estão muito frequentemente em situação de reforma (especialmente no caso de França, Canadá, África do Sul e EUA). Para outros, os que regressam dos países lusófonos e, também, os que regressaram de Itália, Estados Unidos e Bélgica, porque têm bons níveis de trabalho qualificado.

\section{Análise de clusters}

Com o objetivo de sintetizar a informação relativa a este conjunto de variáveis e agregar os países de regresso dos emigrantes em grupos homogéneos foi ensaiada uma análise de clusters. As variáveis consideradas foram: sexo (percentagem de emigrantes do sexo masculino no total de regressados), idade (média etária), 


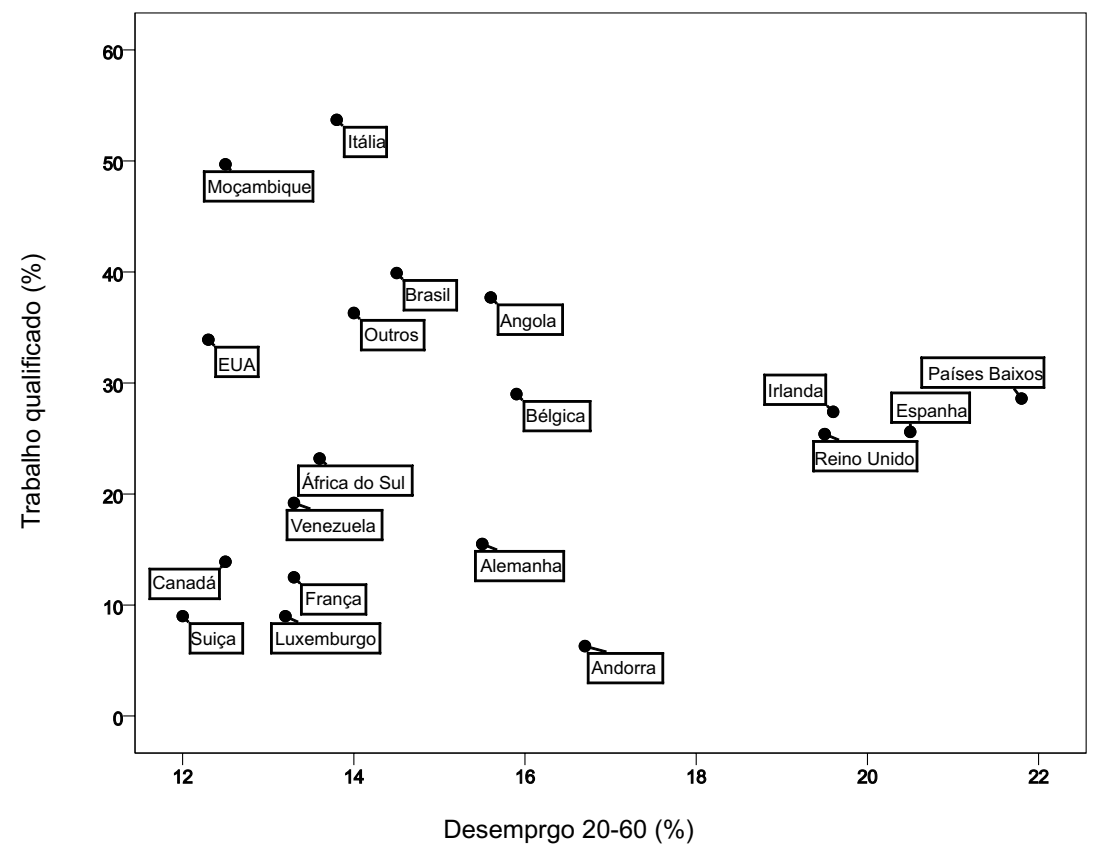

Figura 2 Trabalho qualificado e desemprego

escolaridade (média do número de anos de escolaridade correspondentes ao nível de ensino completado), reforma (percentagem de regressados nesta situação), desempregados (percentagem de desempregados nas idades entre os 20 e os 60 anos), importância das profissões qualificadas (percentagem de emigrantes que tem profissões nas categorias "representantes do poder legislativo e de órgãos executivos, dirigentes, diretores e gestores executivos" e "especialistas das atividades intelectuais e científicas". As características sociodemográficas de cada cluster, ${ }^{5}$ indicando os principais países em causa, são detalhadas no quadro 3.

O primeiro cluster integra os emigrantes que regressam dos destinos com uma longa tradição de emigração. Representam quase metade dos regressos verificados durante a década (47,7\%). Este grupo de emigrantes é caracterizado por uma ligeira predominância do sexo masculino (55,5\%), médias etárias elevadas ( 54,5 anos), escolaridade muito baixa ( 5,6 anos) e uma importantíssima percentagem de reformados $(43,6 \%)$. Dentro deste grupo destaca-se a França pelo seu peso relativo (mais de metade dos regressados que estão neste grupo), mas também por ser o país que melhor expressa duas das características do grupo: a baixa escolaridade (4,9 anos em média) e a importância da reforma (52,8\%). Podemos

5 Foi utilizado o método complete linkage (vizinho mais afastado) e a solução foi depois otimizada com o método K-means. Este último alterou apenas a posição relativa da categoria "outros países". 
Quadro 3 Características sociodemográficas por cluster

\begin{tabular}{lrrrrrrrr}
\hline & $\begin{array}{r}\text { Total } \\
(\mathrm{N})\end{array}$ & $\begin{array}{r}\text { Total } \\
(\%)\end{array}$ & $\begin{array}{c}\text { Homens } \\
(\%)\end{array}$ & $\begin{array}{r}\text { Idade } \\
(\text { anos })\end{array}$ & $\begin{array}{r}\text { Ensino } \\
(\text { anos })\end{array}$ & $\begin{array}{r}\text { Desemp. } \\
(\%)\end{array}$ & $\begin{array}{r}\text { Reforma } \\
(\%)\end{array}$ & $\begin{array}{r}\text { Prof.qualif. } \\
(\%)\end{array}$ \\
\hline França & 57.878 & 27,0 & 55,7 & 56,7 & 4,9 & 13,3 & 52,8 & 12,5 \\
Alemanha & 17.761 & 8,3 & 56,3 & 50,3 & 6,5 & 15,5 & 32,6 & 15,5 \\
EUA & 10.395 & 4,8 & 54,4 & 52,1 & 7,5 & 12,3 & 34,0 & 33,9 \\
Luxemburgo & 5.204 & 2,4 & 57,0 & 46,3 & 6,5 & 13,2 & 24,7 & 9,0 \\
Canadá & 5.141 & 2,4 & 53,9 & 53,7 & 6,2 & 12,5 & 36,2 & 13,9 \\
Venezuela & 3.839 & 1,8 & 53,1 & 56,6 & 5,5 & 13,3 & 20,9 & 19,2 \\
África do Sul & 2.168 & 1,0 & 52,4 & 59,5 & 6,1 & 13,6 & 37,2 & 23,2 \\
Cluster A & $\mathbf{1 0 2 . 3 8 6}$ & $\mathbf{4 7 , 7}$ & $\mathbf{5 5 , 5}$ & $\mathbf{5 4 , 5}$ & $\mathbf{5 , 6}$ & $\mathbf{1 3 , 5}$ & $\mathbf{4 3 , 6}$ & $\mathbf{1 5 , 6}$ \\
Suíça & 27.224 & 12,7 & 56,7 & 44,2 & 6,7 & 12,0 & 10,5 & 9,0 \\
Espanha & 23.790 & 11,1 & 69,2 & 38,5 & 8,6 & 20,5 & 4,7 & 25,6 \\
Reino Unido & 20.747 & 9,7 & 55,9 & 38,3 & 9,6 & 19,5 & 6,6 & 25,4 \\
Países Baixos & 4.558 & 2,1 & 63,9 & 40,3 & 9,2 & 21,8 & 12,1 & 28,6 \\
Bélgica & 4.043 & 1,9 & 53,4 & 43,5 & 9,3 & 15,9 & 15,4 & 29,0 \\
Andorra & 2.209 & 1,0 & 57,3 & 38,9 & 7,1 & 16,7 & 4,8 & 6,3 \\
Irlanda & 1.007 & 0,5 & 68,4 & 36,3 & 10,2 & 19,6 & 2,1 & 27,4 \\
Cluster B & $\mathbf{8 3 . 5 7 8}$ & $\mathbf{3 9 , 0}$ & $\mathbf{6 0 , 4}$ & $\mathbf{4 0 , 6}$ & $\mathbf{8 , 3}$ & $\mathbf{1 7 , 2}$ & $\mathbf{8 , 0}$ & $\mathbf{2 0 , 0}$ \\
Outros & 13.861 & 6,5 & 61,7 & 42,1 & 10,2 & 14,0 & 11,4 & 36,3 \\
Brasil & 6.307 & 2,9 & $\mathbf{5 4 , 0}$ & 49,1 & 10,0 & 14,5 & 22,5 & 39,9 \\
Angola & 4.099 & 1,9 & 75,0 & 47,1 & 9,9 & 15,6 & 14,9 & 37,7 \\
Itália & 2.311 & 1,1 & 51,8 & 36,9 & 12,6 & 13,8 & 5,0 & 53,7 \\
Moçambique & 1.887 & 0,9 & 55,9 & 48,2 & 11,4 & 12,5 & 21,0 & 49,7 \\
Cluster C & $\mathbf{2 8 . 4 6 5}$ & $\mathbf{1 3 , 3}$ & $\mathbf{6 0 , 7}$ & $\mathbf{4 4 , 4}$ & $\mathbf{1 0 , 4}$ & $\mathbf{1 4 , 2}$ & $\mathbf{1 4 , 5}$ & $\mathbf{3 9 , 6}$ \\
\hline
\end{tabular}

Fonte: elaborado pelos autores, com base em INE, Censos 2011.

considerá-lo um cluster tradicional: destinos antigos e regresso predominantemente no final da vida ativa.

O segundo cluster diz respeito aos emigrantes que retornam de novos destinos europeus. Inclui quase $40 \%$ dos emigrantes adultos regressados na década. Possui características diversas do anterior: há uma maior percentagem de homens (60,4\%), é o grupo mais jovem (em média 40,6 anos), a escolaridade é mais elevada $(8,3$ anos) e tem a menor proporção de reformados $(8,0 \%)$. Para além de serem o grupo mais jovem, são também o conjunto onde a incidência do desemprego é maior $(17,2 \%)$. A sua juventude e a importância relativa do desemprego podem indiciar uma maior tendência para a reemigração e circulação, para os mesmos ou para outros destinos.

Neste grupo de países têm grande importância a Suíça, a Espanha e o Reino Unido. Os emigrantes que regressaram da Suíça apresentam um perfil parcialmente semelhante ao do primeiro cluster: são os mais velhos (44,2 anos) e os menos escolarizados (6,7 anos de escolaridade) deste grupo; caracterizam-se ainda pelas reduzidas proporções de desempregados $(12,0 \%)$ e de trabalhadores qualificados $(9,0 \%)$. No entanto, distinguem-se claramente do primeiro cluster porque têm uma menor proporção de reformados. De Espanha e do Reino Unido regressam emigrantes mais jovens (em média 38,5 e 38,3 anos), que raramente são reformados (4,7\% e 6,6\%), apresentam escolaridades intermédias ( 8,6 e 9,6 anos), empregam-se com alguma frequência em profissões qualificadas ( $25,6 \%$ e $25,4 \%)$, mas têm uma grande percentagem de desempregados $(20,5 \%$ e $19,5 \%)$ No caso de Espanha 
retornam fundamentalmente homens (69,2\%) e de Inglaterra volta uma emigração mais equilibrada relativamente a este aspeto $(55,9 \%)$.

Globalmente, e apesar de alguma heterogeneidade, este segundo cluster parece ser um grupo que pode ser caracterizado como uma renovação com elementos de continuidade: destinos europeus, para trabalhos mais e menos qualificados, e situações após o regresso bastante diferenciadas entre si.

No terceiro cluster encontramos os emigrantes que regressam de países lusófonos e de Itália, entre outros. Representam a minoria dos emigrantes que voltaram nesta década: apenas $13,3 \%$. É também uma emigração tendencialmente mais masculina (especialmente no caso de Angola - 75\%), com uma média etária que se situa entre os dois grupos anteriores, e é, fundamentalmente, o grupo onde a escolaridade é mais elevada (em média estudaram durante 10,4 anos). É por isso natural que aqui se encontre a maior proporção de indivíduos com emprego qualificado (39,6\%). Em compensação, o desemprego e a reforma têm valores intermédios $(14,2 \%$ e $14,5 \%)$, tal como acontecia com a idade. É um grupo onde também se encontram perfis diferenciados: os regressados do Brasil são mais velhos e incluem mais reformados, os originários de Itália e de Moçambique são aqueles em que o trabalho qualificado tem uma maior expressão, enquanto de Angola regressam fundamentalmente homens. ${ }^{6}$

Com a exceção de Itália, este último cluster agrupa sobretudo países de fora da Europa que conheceram uma reativação recente dos fluxos. Este grupo corresponde tendencialmente aos emigrantes mais escolarizados e com uma melhor inserção no mercado de trabalho quando regressam.

\section{Regresso e circulação}

Como referimos no enquadramento teórico inicial, vários indícios apontam para uma importância significativa da circulação nas últimas décadas. A análise do regresso de emigrantes pode dar pistas no sentido da confirmação desta hipótese, nomeadamente através da consideração das taxas de regresso de cada um dos países de emigração. A probabilidade de, na última década, um emigrante português regressar a Portugal pode ser aproximada a partir da combinação do número de regressos registado, entre 2001 e 2011, com a população de origem portuguesa residente nesses países nessas duas datas.

Para além disso, uma vez que a probabilidade de emigração pode aumentar com o número de saídas anteriores (DaVanzo, 1981), devido à posse de melhor informação ou à aquisição de competências que podem ser usadas noutro contexto, podemos admitir como hipótese de trabalho que, quanto maior for a taxa de

6 O conjunto agregado sob a designação "outros" engloba países de onde regressaram menos de 1000 emigrantes na década, cada um representando menos de $0,5 \%$ do total de regressados. Tratar-se-á, necessariamente, de um conjunto heterogéneo. Porém, globalmente é constituído por indivíduos que se aproximam dos valores do terceiro cluster, sendo ligeiramente mais jovens, com menos reformados e com menos trabalho qualificado. 
Quadro 4 Taxas de regresso com base nos censos

\begin{tabular}{lcccc}
\hline País de emigração & Regressos & $\begin{array}{c}\text { População com } \\
\text { naturalidade } \\
\text { portuguesa em 2001 }\end{array}$ & $\begin{array}{c}\text { População com } \\
\text { naturalidade } \\
\text { portuguesa em 2011 }\end{array}$ & $\begin{array}{c}\text { Taxa } \\
\text { de regresso (\%) }\end{array}$ \\
\hline Irlanda & 1.098 & 590 & 2.246 & 77,4 \\
Itália & 2.446 & 4.158 & 5.241 & 52,0 \\
Países Baixos & 4.880 & 10.218 & 14.430 & 39,6 \\
Reino Unido & 23.077 & 36.556 & 92.065 & 35,9 \\
Espanha & 26.615 & 56.359 & 98.975 & 34,3 \\
Alemanha & 18.809 & 70.100 & 75.110 & 25,9 \\
Suíça & 29.469 & 100.975 & 169.458 & 1,8 \\
Luxemburgo & 5.720 & 41.690 & 60.897 & 10,1 \\
França & 60.582 & 581.062 & 617.235 & 8,7 \\
Venezuela & 3.950 & 53.447 & 37.326 & 4,3 \\
Brasil & 7.542 & 213.203 & 137.973 & 3,8 \\
Canadá & 5.525 & 153.530 & 140.310 & \\
\hline
\end{tabular}

Fonte: elaborado pelos autores, com base em INE, Censos 2011 (regressos) e Observatório da Emigração (população com naturalidade portuguesa em 2001 e 2011).

regresso de um país, maior será a possibilidade de um emigrante se envolver em novas saídas - isto é, dar início a um processo de circulação.

A taxa de regresso calculada neste texto resulta do rácio entre os regressos que aconteceram entre janeiro de 2001 e março de 2011 (consideradas todas as idades), segundo o Censo português de 2011, e o stock médio de população com naturalidade portuguesa durante esse mesmo período, segundo os censos dos países de destino (Dumont e Spielvogel, 2008). Recorde-se que este stock médio resulta quer de chegadas acontecidas em décadas anteriores, quer de chegadas durante a década mais recente. Do mesmo modo, os regressos de emigrantes verificados em 2001-2011 também resultam de fluxos desta e de outras décadas. Assim, a taxa de regressos pode ser interpretada como a probabilidade de um emigrante português que residia durante a década passada num país estrangeiro regressar nessa década a Portugal. ${ }^{7}$

Para um emigrante português residente num país estrangeiro durante a primeira década do século XXI, a probabilidade de regressar a Portugal é muito diferenciada consoante o país de destino (quadro 4). Os países de emigração mais antiga têm taxas de regresso muito baixas, situando-se abaixo de 11,5\% (Canadá, Brasil, Venezuela, França e Luxemburgo). ${ }^{8}$ Na posição contrária, encontram-se os emigrantes portugueses na Irlanda e na Itália, onde as taxas excedem os 50\%. Logo

7 Não se trata da probabilidade de um emigrante que foi em 2001-2011 regressar, nem da probabilidade de um emigrante que foi em qualquer uma das décadas ter regressado desde que emigrou. Trata-se de um indicador sem leitura longitudinal, mas que tem uma leitura conjuntural. Ao relacionar a população presente num país, num dado período, com a que regressa desse país, nesse período, aproxima-se da noção de probabilidade de retorno ao país de origem, durante esse período.

8 Se se considerassem, ao invés dos censos, os valores das estimativas populacionais da ONU, concluir-se-ia o mesmo para os emigrantes dos EUA e África do Sul. 
a seguir encontram-se as taxas de regresso dos emigrantes portugueses nos Países Baixos, Reino Unido e Espanha, situadas entre 34\% e 40\%. ${ }^{9}$ Os países com maior taxa de regressos são também aqueles para os quais se sabe que a emigração é relativamente recente, o que sugere migrações de menor duração, eventualmente repetíveis. Estes valores traduzem também o facto de muitos regressos tenderem a ocorrer não muito tempo depois da emigração. Recorde-se ainda que, em alguns destes países, a população que regressou era bastante jovem e detinha uma elevada taxa de desemprego.

\section{Taxa de regresso e população emigrada}

Comparando os valores da taxa de regresso com a população de naturalidade portuguesa a residir nesses mesmos países, destacam-se, por um lado, países como a Irlanda e a Itália, por possuírem um baixo contingente de população residente e uma elevada taxa de retorno. Mediante este cenário podemos estar perante situações de: (a) pessoas que emigraram, não conseguiram integrar-se e regressaram, $o$ que significaria um fracasso à luz das perspetivas tradicionais; ou (b) migração circular. Tendo em conta a elevada escolaridade e proporção de sujeitos a desempenhar profissões qualificadas após o regresso, é mais provável que se esteja perante a segunda hipótese.

No extremo oposto destaca-se a França, pelo elevado número de população residente e reduzida taxa de retorno. Neste caso, porém, não é garantido falar de uma baixa propensão para o retorno, uma vez que muitos dos fluxos antigos para este país se têm transformado em regressos ao longo das décadas, não se concentrando estes últimos na década mais recente. Apenas uma perspetiva longitudinal permitiria apurar a verdadeira dimensão do retorno de França.

\section{Taxa de regresso e idade}

Tendo em conta a relação entre taxa de regresso e idade, os regressos são mais expressivos a partir dos países de onde regressa uma população mais jovem e muito menos expressivos quando dos países de emigração regressam emigrantes com uma média etária mais elevada (figura 3). Esta relação inversa entre a idade média em que regressam os emigrantes e a propensão para o regresso é um dos sinais que aponta para um aumento dos movimentos de circulação: é dos países de emigração mais recente que regressa, agora, uma população jovem, enquanto os países com maior tradição de emigração apresentam taxas de regresso mais baixas.

9 Não foram calculadas as taxas de regresso de Angola e Moçambique devido à dificuldade em obter estimativas fiáveis para a população com origem portuguesa durante esse período. O mesmo se aplica a todos os outros países sem dados censitários no Observatório da Emigração (fonte da informação recolhida para este efeito). 


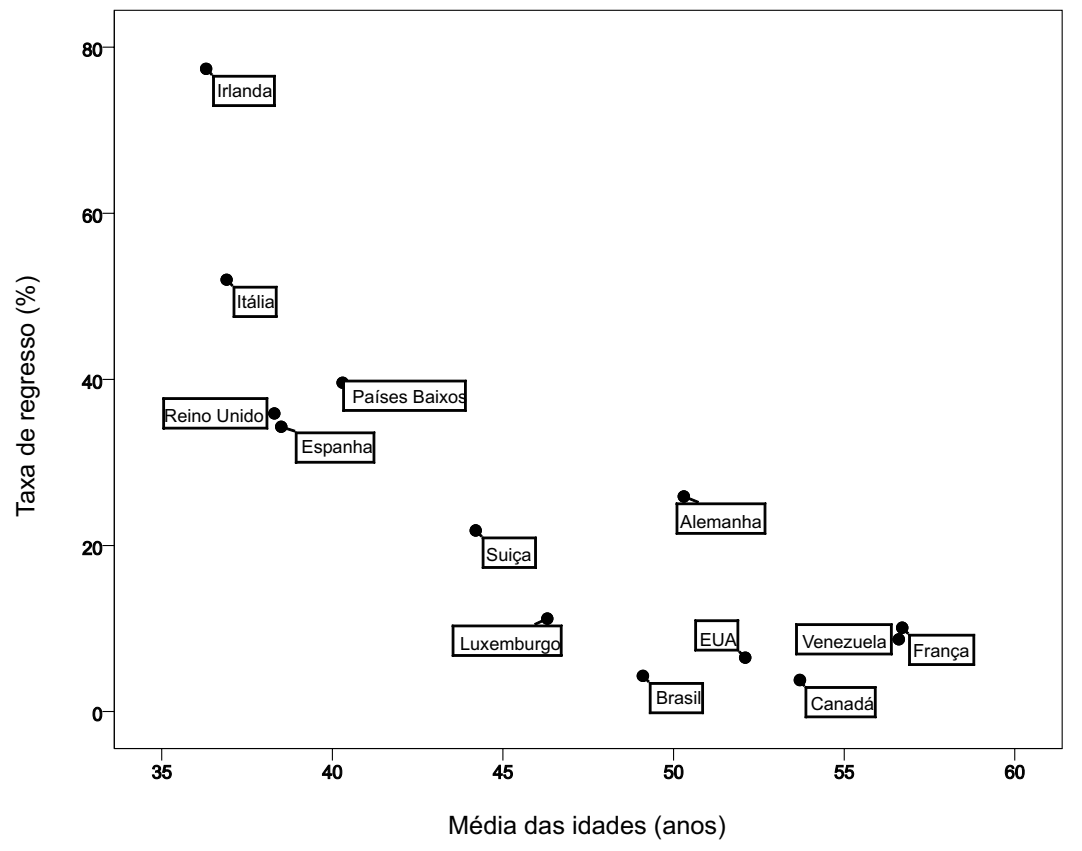

Figura 3 Taxa de regresso e idade

Fonte: elaborado pelos autores, com base em INE, Censos 2011.

\section{Taxa de regresso e escolaridade}

Uma outra linha central desta análise prende-se com a qualificação da população que partiu e que regressou na última década (figura 4). Parece haver uma estreita relação entre a maior propensão para o regresso de emigrantes e a escolaridade dos que regressam: os países com menor taxa de regresso são aqueles de onde regressam emigrantes menos escolarizados - o cluster da emigração de destinos e regressos tradicionais centrados no final da vida ativa, para onde foi e de onde regressa uma população muito pouco escolarizada.

Por seu lado, à medida que aumenta a escolaridade verifica-se que também aumenta a taxa de regresso dos emigrantes. É pouco provável que regressem fundamentalmente os mais escolarizados e que permaneçam nos países de emigração os menos escolarizados. É natural que esta maior escolarização traduza os maiores níveis de educação do próprio fluxo de emigração para esses países, associado ao aumento dos níveis de escolarização verificado nas últimas décadas na sociedade portuguesa.

Parece indiciar-se, assim, uma tendência para a circulação dos mais jovens e dos mais escolarizados, se comparados com a tendência para o regresso verificada nos emigrantes que voltam de países de emigração tradicional. Porém, há que ter em conta que, destes países, já houve muitos regressos nas décadas anteriores. 


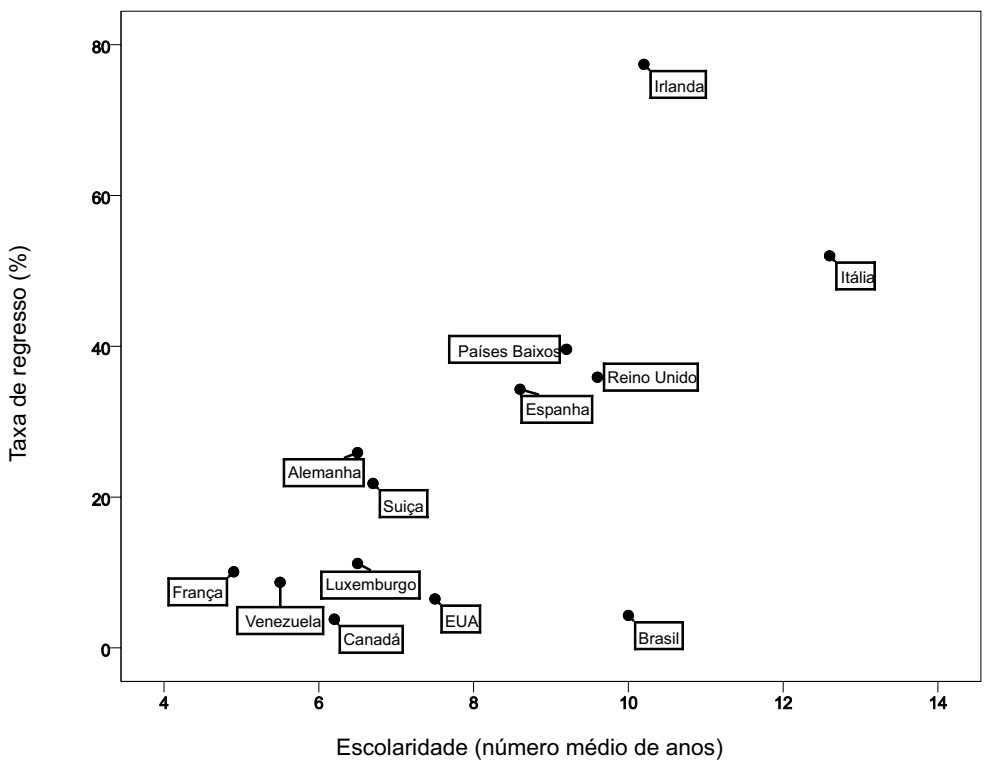

Figura 4 Taxa de regresso e escolaridade

Fonte: elaborado pelos autores, com base em INE, Censos 2011.

\section{Considerações finais}

Os números apresentados neste texto confirmam que o regresso de emigrantes continua a ser uma realidade no início do século XXI. Mais do que um projeto imaginado, os fluxos são numerosos e consistentes ao longo da primeira década do século. Como vimos na secção inicial deste texto, esta realidade não é muito diferente da que se conhece para contextos históricos anteriores. São assim de novo desmentidas algumas perspetivas simplistas sobre a emigração, quando se admite o caráter tendencialmente unilateral dos movimentos ou a irreversibilidade da fixação nos países de destino. Apesar de o tema do regresso nem sempre constar da agenda dos investigadores, este movimento é frequente e adquire contornos complexos - como prova a experiência portuguesa mais recente.

Antes de mais, o volume de regressos apurado para o período de 2001-2011 é considerável. Segundo os resultados do Censo de 2011, existiam cerca de $233 \mathrm{mil}$ indivíduos nascidos em Portugal que residiram durante um período contínuo de mais de um ano no estrangeiro e que, durante aquela década, regressaram ao país. Como foi notado, esse número subavalia o número real de regressos, pois muitos indivíduos nesta situação poderão ter reemigrado ou falecido antes de 2011. Ora admitir que terão regressado a Portugal mais do que 23 mil emigrantes por ano é confirmar a importância quantitativa deste movimento, quando comparado com 
os fluxos anuais de emigração da década passada e com a imigração de população estrangeira ocorrida no mesmo período.

A análise das características dos emigrantes regressados permite concluir, por sua vez, por perfis muito distintos - o que confirma a hipótese adiantada no início deste texto segundo a qual novos padrões de emigração poderão originar novos tipos de regresso.

O perfil tradicional do regresso encontra-se no caso dos países de emigração mais antiga, exemplarmente ilustrado por França. Destes países regressaram, na última década, sobretudo emigrantes em idade adulta avançada (perto de 60 anos), com baixa escolaridade e em muitos casos reformados (perto de metade). A imagem tradicional da emigração portuguesa tem aqui o seu espelho. Tal como era descrito nos textos sobre o regresso nos anos 80 do século XX (cf. Rato, 2001), este grupo corresponde aos emigrantes económicos da segunda metade do século XX, que encetaram projetos migratórios de longa duração, antecedendo um regresso perto do final da vida ativa.

O segundo grupo de emigrantes regressados provém, sobretudo, de países europeus de emigração mais recente, como a Suíça, a Espanha e o Reino Unido. Embora exista diferenciação entre estes países, trata-se em geral de indivíduos mais jovens (em média, cerca de 40 anos à data do Censo), com uma escolaridade mais elevada, poucas vezes em situação de reforma e, sobretudo, detendo elevada taxa de desemprego. Estes números sugerem que parte das migrações mais recentes, mais qualificadas do que as tradicionais, tende a ser breve. A situação de desemprego após o regresso permite acreditar que novos projetos de emigração se seguirão. As teses do transnacionalismo e da circulação poderão resultar tanto de projetos livremente construídos, como dos constrangimentos criados por um mercado de trabalho mais flexível e precário, menos favorável a projetos de longa duração.

O terceiro grupo de emigrantes regressados é oriundo sobretudo de países lusófonos, nomeadamente Brasil, Angola e Moçambique. Estes indivíduos apresentam uma idade adulta menos avançada que os do primeiro grupo (rondando os 44 anos), têm a escolaridade mais elevada de todos os grupos, ocupam, após o regresso, profissões qualificadas, estão poucas vezes em situações de reforma ou desemprego. Tudo indica que se trata de fluxos recentes, destinados a ocupar postos qualificados nos mercados de trabalho dos países de destino, por períodos de tempo limitados. Mais uma vez, os regressos tradicionais dão lugar a novos perfis, mais adequados aos contextos migratórios contemporâneos.

Vários destes valores parecem confirmar o aumento recente das lógicas de circulação migratória, caracterizadas por permanências mais curtas, maior frequência de regressos e maior número de movimentos entre países. Esta asserção é reforçada com o cálculo das taxas de regresso por país. Enquanto dos países de emigração tradicional a população regressada na primeira década do século XXI é proporcionalmente escassa - embora seja verdade que os regressos destes países se foram acumulando ao longo das últimas décadas - encontramos fortes volumes relativos de regressados de países de emigração mais recente. Aparentemente, muitos dos fluxos dirigidos nos últimos anos para novos destinos, europeus ou 
outros, não se sedimentam, dando lugar a muitos retornos ao país. Dada a debilidade da reintegração em Portugal, sobretudo ilustrada pelo peso do desemprego, são muito prováveis novas saídas.

Em síntese, a evidência tratada neste texto permite contextualizar o mapa do retorno de emigrantes portugueses após a viragem do século. Os estudos anteriores sobre a emigração tradicional já admitiam alguma importância desta contracorrente migratória - mesmo se, em muitos casos, o regresso era apenas um mito e permanecia como realidade imaginada. Este estudo permite concluir que os retornos - como a emigração - não terminaram e tendem a revestir novos contornos, eles próprios resultantes de um contexto dinâmico das migrações mundiais. Novos padrões de emigrantes e novos destinos migratórios dão lugar a novas tipologias de regresso, que parecem aproximar-se de uma lógica de circulação.

\section{Referências bibliográficas}

Álvarez Silvar, G. (1997), La Emigración de Retorno en Galicia (1970-1997), Santiago de Compostela, Xunta de Galicia.

Alves, J. F. (1994), Os Brasileiros. Emigração e Retorno no Porto Oitocentista, Porto, Faculdade de Letras da Universidade do Porto, tese de doutoramento.

Antunes, M. L. Marinho (1981), “Migrações, mobilidade social e identidade cultural: factos e hipóteses", Análise Social, XVII (65), pp. 17-27.

Baganha, M. I., e P. Góis (1998-1999), “Migrações internacionais de e para Portugal: o que sabemos e para onde vamos?", Revista Crítica de Ciências Sociais, 52-53, pp. 229-280.

The World Bank (2005), 2005 World Development Indicators, Washington, DC, The World Bank. Bauman, Z (1998), Globalization. The Human Consequences, Oxford, Polity Press.

Cairns, D., J. Sardinha, e N. C. Tiesler (2014), “Mapping the return migration research field", CIES e-Working Paper, n. ㅇ 197/2014.

Candeias, P., B. Ferreira, e J. Peixoto (2014), “Emigração portuguesa: o que temos vindo a estudar e o que nos falta saber - uma análise bibliométrica entre 1980 e 2013", População e Sociedade, 22, pp. 11-31.

Candeias, P., P. Góis, J. C. Marques, e J. Peixoto (2014), “Emigração portuguesa: bibliografia comentada (1980-2013)", Socius Working Papers, n.o 01/2014.

Carling, J., e M. B. Erdal (2014), "Return migration and transnationalism: how are the two connected?", International Migration, 52 (6), pp. 2-12.

Cassarino, J.-P. (2013), “Teorizando sobre a migração de retorno: uma abordagem conceitual revisitada sobre migrantes de retorno", REMHU - Revista Interdisciplinar da Mobilidade Humana, 41, pp. 21-54.

Castro-Almeida, C. (1989), “Immigration et espaces de mobilité en Europe: le cas de l'immigration portugaise en France", Espaces et Societés, 54-55, pp. 157-168.

Cavalcanti, L., e S. Parella (2013), "El retorno desde una perspectiva transnacional”, REMHU - Revista Interdisciplinar da Mobilidade Humana, XXI (41), pp. 9-20.

Constant, A., e K. F. Zimmermann (2011), “Circular and repeat migration: counts of exits and years away from the host country", Population Research and Policy Review, 30, pp. 495-515. 
Cordeiro, A. (2002), “Le va-et-vient des portugais en Europe”, Projet, 272, pp. 63-68.

DaVanzo, J. (1981), “Repeat migration, information costs, and location-specific capital”, Population and Environment, 4 (1), pp. 45-73.

Delicado, A. (2010a), "Going abroad to do science: mobility trends and motivations of Portuguese researchers", Science Studies, 23 (2), pp. 36-59.

Delicado, A. (2010b), “O retorno dos 'cérebros': regresso e reintegração dos investigadores portugueses em mobilidade", Revista Iberoamericana de Ciencia, Tecnología y Sociedad, 5 (15), pp. 185-218.

Duany, J. (2002), “Mobile livelihoods: the sociocultural practices of circular migrants between Puerto Rico and the United States", International Migration Review, 36 (2), pp. 355-388.

Dumont, J.-C., e G. Spielvogel (2008), “Return migration: a new perspective”, em OECD (org.), International Migration Outlook, OECD Publishing, pp. 161-222.

Faist, T. (2013), “The mobility turn: a new paradigm for the social sciences?", Ethnic and Racial Studies, 36 (11), pp. 1637-1646.

Favell, A. (2008), Eurostars and Eurocities. Free Movement and Mobility in an Integrating Europe, Oxford, Blackwell Publishers.

Hagan, J., K. Eschbach, e N. Rodriguez (2008), “U.S. deportation policy, family separation, and circular migration", International Migration Review, 42 (1), pp. 64-88.

Hugo, G. (1977), “Circular migration”, Bulletin of Indonesian Economic Studies, 13 (3), pp. 57-66.

King, R., e A. Christou (2011), “Of counter-diaspora and reverse transnationalism: return mobilities to and from the ancestral homeland", Mobilities, 6 (4), pp. 451-466.

Marques, J. C. L. (2008), Os Portugueses na Suiça. Migrantes Europeus, Lisboa, Imprensa de Ciências Sociais.

Monteiro, P. F. (1994), Emigração. O Eterno Mito do Retorno, Oeiras, Celta Editora.

Neto, F. (2010), “Re-acculturation attitudes among adolescents from returned Portuguese immigrant families", International Journal of Intercultural Relations, 34 (3), pp. 221-232.

Park, R. E., e E. W. Burgess (1921), Introduction to the Science of Sociology, Chicago, The University of Chicago Press.

Pascual de Sans, A. (1983), “Los movimientos migratorios de retorno: significación y perspectivas", Documents d'Análisi Geográfica, 3, pp. 47-69.

Piloto, A. (2010), O Concelho de Vila do Conde e o Brasil. Emigração e Retorno 1865-1913, Porto, Faculdade de Letras da Universidade do Porto, tese de doutoramento.

Pinho, F., e R. P. Pires (2013), Espanha. Emigração Portuguesa por País, 1, Lisboa, Observatório da Emigração, Instituto Universitário de Lisboa (ISCTE-IUL), CIES-IUL e DGACCP.

Pires, R. P., et al. (1984), Os Retornados. Um Estudo Sociográfico, Lisboa, Instituto de Estudos para o Desenvolvimento.

Pires, R. P., F. L. Machado, J. Peixoto, e M. J. Vaz (2010), Portugal. Atlas das Migrações Internacionais, Lisboa, Tinta-da-China e Fundação Calouste Gulbenkian.

Pires, R. P., C. Pereira, J. Azevedo, e A. C. Ribeiro (2014), Emigração Portuguesa. Relatório Estatístico 2014, Lisboa, Observatório da Emigração.

Poinard, M. (1983a), “Emigrantes portugueses: o regresso”, Análise Social, XIX (75), pp. 29-56. 
Poinard, M. (1983b), “Emigrantes retornados de França: a reinserção na sociedade portuguesa”, Análise Social, XIX (76), pp. 261-296.

Posel, D., e C. Marx (2013), “Circular migration: a view from destination households in two urban informal settlements in South Africa", The Journal of Development Studies, 49 (6), pp. 819-831.

Rallu, J. L., F. Muñoz-Perez, e M. J. Carrilho (2000), “Return migration from Europe to Spain and Portugal", Studi Emigrazione/Migration Studies, 37 (139), pp. 625-649.

Rato, H. (2001), “O retorno dos emigrantes”, Janus - Anuário de Relações Exteriores, 2001, pp. 164-165.

Ravenstein, E. G. (1885), “The laws of migration”, Journal of the Statistical Society of London, 48 (2), pp. 167-235.

Recchi, E., e A. Favell (2009), Pioneers of European Integration, Cheltenham, Edward Elgar.

Rocha-Trindade, M. B. (1983), “O regresso imaginado”, Nação e Defesa, 28, pp. 87-97.

Sardinha, J. (2011), “'Returning' second-generation Portuguese-Canadians and Portuguese-French return motivations and sense of belonging", Journal of Mediterranean Studies, 20 (2), pp. 231-254.

Sayad, A. (2000), "O retorno: elemento constitutivo da condição do imigrante", Revista Travessia, 13 (número especial), pp. 7-32.

Silva, M., R. R. Amaro, G. Clausse, C. Cónim, M. Matos, M. Pisco, e L. M. Seruya (1984), Retorno, Emigração e Desenvolvimento Regional em Portugal, Lisboa, Instituto de Estudos para o Desenvolvimento.

Sinatti, G. (2011), “'Mobile transmigrants' or 'unsettled returnees'? Myth of return and permanent resettlement among Senegalese migrants", Population, Space and Place, 17 (2), pp. 153-166.

Unger, K. (1986), "Return migration and regional characteristics: the case of Greece”, em R. King (org.), Return Migration and Regional Economic Problems, Londres, Croom Helm, pp. 129-151.

Vilar, J. B. (2003), “El retorno en las migraciones españolas con Europa en el siglo XX: precisiones conceptuales y anotaciones bibliográficas", Papeles de Geografía, 37, pp. 261-276.

Zelinsky, W. (1971), "The hypothesis of the mobility transition", Geographical Review, 61 (2), pp. 219-249.

Isabel Tiago de Oliveira (corresponding author). Professora auxiliar. Instituto Universitário de Lisboa (ISCTE-IUL), Centro de Investigação e Estudos de Sociologia (CIES-IUL), Av. das Forças Armadas, 1649-026 Lisboa, Portugal. E-mail: isabel.oliveira@iscte.pt

Pedro Candeias. Bolseiro de doutoramento. Instituto de Ciências Sociais (ICS), Universidade de Lisboa, Av. Prof. Aníbal de Bettencourt, 9, 1600-189 Lisboa, Portugal. E-mail: pedromecandeias@gmail.com 
João Peixoto. Professor catedrático. Instituto Superior de Economia e Gestão (ISEG), Centro de Investigação em Sociologia Económica e das Organizações (SOCIUS/CSG), Universidade de Lisboa, Rua Miguel Lupi, 20, 1249-078 Lisboa, Portugal. E-mail: jpeixoto@iseg.ulisboa.pt

Joana Azevedo. Professora auxiliar convidada. Instituto Universitário de Lisboa (ISCTE-IUL), Centro de Investigação e Estudos de Sociologia (CIES-IUL), Av. das Forças Armadas, 1649-026 Lisboa, Portugal. E-mail: joana.azevedo@iscte.pt

Jorge Macaísta Malheiros. Professor associado. Instituto de Geografia e Ordenamento do Território (IGOT), Universidade de Lisboa, Rua Branca Edmée Marques, 1600-276 Lisboa, Portugal. E-mail: jmalheiros@campus.ul.pt

Receção: 16 de julho de 2015 Aprovação: 12 de novembro de 2015 
